Supplement of SOIL, 2, 287-298, 2016

http://www.soil-journal.net/2/287/2016/

doi:10.5194/soil-2-287-2016-supplement

(C) Author(s) 2016. CC Attribution 3.0 License.

(c) (i)

Supplement of

\title{
Climate and soil factors influencing seedling recruitment of plant species used for dryland restoration
}

M. Muñoz-Rojas et al.

Correspondence to: Miriam Muñoz-Rojas (miriammunozrojas@gmail.com; miriam.munoz-rojas@uwa.edu.au)

The copyright of individual parts of the supplement might differ from the CC-BY 3.0 licence. 


\section{Supplementary material}
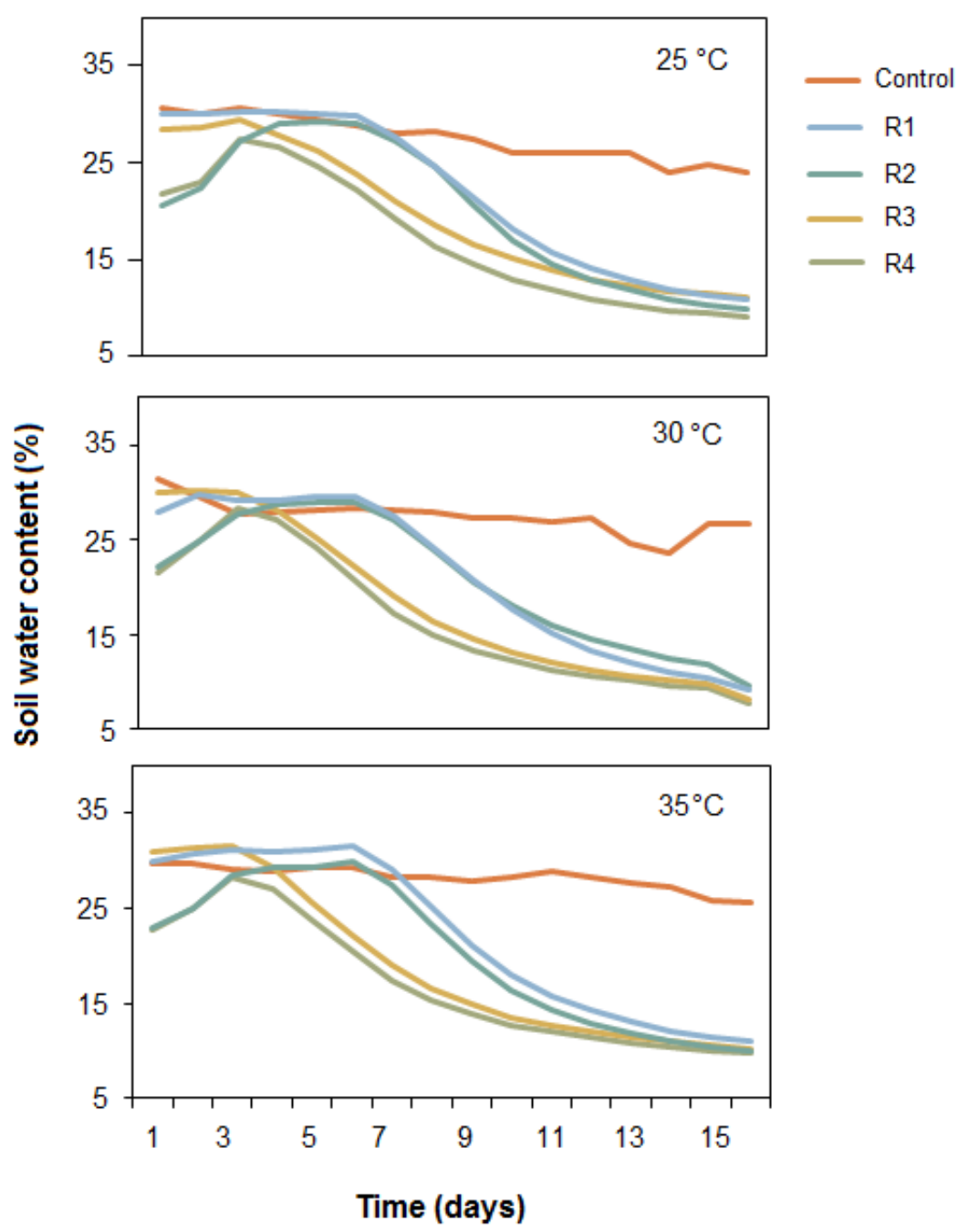

Figure S1. Variation in soil water content (\%) with time (days) for climate scenarios ( $\mathrm{T}=25,30$ and $\left.35^{\circ} \mathrm{C}\right)$. Watering treatments (control, R1, R2, R3 and R4) as described in Table 1. 


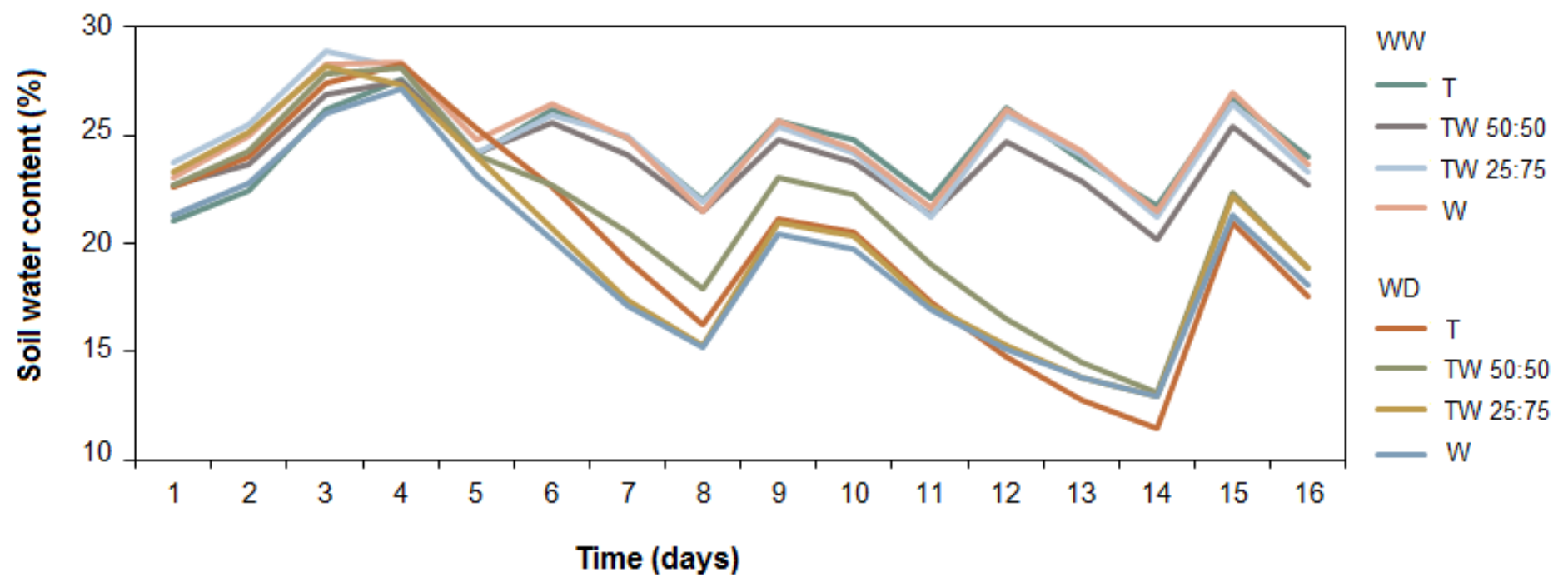

Figure S2. Variation in soil water content (\%) with time (days) for different watering treatments (WW; well watered and WD: water deficit) and growth media types (T: 100\% topsoil, TW 50:50: mix of topsoil and waste at 50:50 ratio, TW 25:75: mix of topsoil and waste at 75:25 ratio and W: 100\% waste). 